\title{
Self-healing stimulated by crystalline admixtures in chloride rich environments: is it possible to extend the structure service life?
}

\author{
E. Cuenca ${ }^{1}$, E.M.Gastaldo Brac ${ }^{2}$, S. Rigamonti ${ }^{1}$, V. Violante ${ }^{2}$ and L. Ferrara ${ }^{1}$ \\ ${ }^{1}$ Politecnico di Milano, Department of Civil and Environmental EngineeringPiazza Leonardo da \\ Vinci 32, 20133, Milano (Italy) \\ ${ }^{2}$ Penetron Italia, via Italia 2/B, 10093, Collegno (Italy)
}

Keywords: Self-healing concrete, crystalline admixture, chlorides, service life.

\section{INTRODUCTION}

Design code prescritpions on the service life of ordinary reinforced concrete structures may be difficult to be fulfilled in highly aggressive environments, in which premature degradation of the structural performance is most likely to occur. In these situations, in order to avoid expensive repair activities, advanced systems such as self-healing concrete could be adopted. In the last decade, researchers started to look at this functionality as a way to solve degradation problems in chloride-laden environments. If a significant degree of crack sealing is achieved, the mechanical and physical properties of a cracked element tend to those of an identical uncracked element, thus resulting into a slower penetration rate of aggressive substances.

In the broad literature on the stimulation/engineering and experimental assessment of selfhealing functionalities in concrete [1,2] and cement based materials, a relatively few number of studies has addressed the effectiveness of healing in reducing the chloride diffusion. As far as autogenous healing is concerned, several authors agreed that self-healing is able to induce a full recovery of the chloride diffusion resistance for crack widths below a certain threshold, in the range of few tens of microns [3-5]. Borg et al. [6] studied the crack sealing capacity of mortars containing supplementary cementitious materials (fuel ash and silica fume) or crystalline admixture in chloride-rich environments. They observed that sea-water may lead to an enhancement of the self-healing capacity of mortars with respect to distilled water, especially for higher chloride contents. They noticed that both the addition of fuel ash (with a replacement ratio lower than 20\%) and silica fume (with a content of $15 \%$ by mass of cement) have a beneficial effect on the sealing capacity of cracks up to intermediate widths $(0.15-0.3 \mathrm{~mm})$. The mix containing the crystalline admixture, thanks to its hydrophilic behavior, guaranteed the highest crack sealing capacity in almost all the investigated conditions, especially for cracks up to $0.3 \mathrm{~mm}$. Li et al. [7] tested high performance fiber reinforced concrete specimens pre-loaded up to $0.5 \%, 1.0 \%$, and $1.5 \%$ tensile strain level and immersed in a $3 \%$ chloride solution for 30,60 and 90 days. When they re-loaded the specimens after curing, they found that, due to selfhealing, specimens partially recovered some of their mechanical features. Moreover, the results showed that under severe chloride exposure, the specimens remained durable with a good crackcontrolling capability. Ling et al. [8] studied the effects of self-healing cracks in bacterial concrete on the penetration of chlorides. They considered ordinary Portland cement mortar specimens (control) and one mortar containing a microbial self-healing agent. It was observed that self-healing led to a reduction of chloride content for both mixes, but the chloride content in the specimens having the self-healing agent was lower. Van Belleghem et al. [9] used a concrete mixture containing fly ash and a polyurethane-based healing agent encapsulated into glass capsules. Some of the specimens were pre-cracked up to a crack width of $300 \mu \mathrm{m}$. The results 
showed that chloride ingress depends on the crack opening and increases almost exponentially along the depth of the crack. After the curing time, it was observed that the self-healing agent led to a reduction of the chloride ingress rate up to $75 \%$. Maes et al. [10] also studied the improvement in service life of concrete specimens suffering chloride attack due to self-healing, introducing into their life prediction model a variable depending on the crack width.

The main problem in exploiting this phenomenon is its reliability. For this reason, an experimental campaign, was carried out which, besides aiming at assessing the influence of the environmental conditions on the strength development, focused on the recovery of chloride diffusion resistance in pre-cracked specimens. The investigation was also meant to obtain useful indications to design and build the "ordinary reinforced concrete" cell of a water basin in a geothermal power plant, to be compared on the one hand with the current construction practice, which requires wall as thick as $400 \mathrm{~mm}$ for mere durability issues, and, on the other with advanced solutions in which Ultra High Durability Concretes will be employed, in the framework of the H2020 project ReSHEALience [11].'

\section{EXPERIMENTAL PROGRAMME}

Two mixes, differing because of the presence of a crystalline admixture, were considered, whose mix proportions are summarized in Table 1.

\begin{tabular}{|c|c|c|}
\hline Component & Without CA $\left(\mathrm{kg} / \mathrm{m}^{3}\right)$ & With CA $\left(\mathrm{kg} / \mathrm{m}^{3}\right)$ \\
\hline Portland cement CEM II 42,5 R & 360 & 360 \\
\hline Water & 180 & 180 \\
\hline Fine aggregate (sand 0-4 mm) & 814 & 811 \\
\hline Coarse aggregate (gravel 4-16 mm) & 1077 & 1077 \\
\hline Superplasticizer admixture & 3.5 & 3.5 \\
\hline Crystalline admixture (Penetron Admix $\circledR)$ & $=$ & 2.9 \\
\hline
\end{tabular}

Table 1. Concrete compositions

First, the average compressive strength of concrete after 7, 14, 28, 56 and 84 days curing in the above-listed environmental conditions was measured. For each curing time and type of concrete, at least 3 cylindrical specimens $200 \mathrm{~mm}$ high and with $100 \mathrm{~mm}$ diameter were tested.

For the measurement of the effects of healing on chloride diffusion resistance, $100 \mathrm{~mm}$ high cylinders with a $100 \mathrm{~mm}$ diameter were used. 7 or 28 days after casting, half of the specimens were pre-cracked by means of a splitting test. The two halves were then reunited, the crack width was visually analyzed by means of an image analysis software [12], and all the samples were cured for 1, 3 or 6 additional months, both permanently immersed in a $16.5 \% \mathrm{NaCl}$ solution or subjected to wat/dry cycles in the same solutions. After curing, a visual inspection of the healed pre-cracked specimens was carriedout by means of an electronic microscope and an imageediting software, aimed at quantifying the extent of crack closure. Fourteen pictures of each crack were taken both immediately after pre-cracking and at the end of each curing time. These pictures were then processed by means of the image-editing software, thus allowing the identification of the surface crack width before and after the healing time and so the determination of the percentage of closure. Moreover, for each considered environmental condition, specimens were subjected to chemical titration (RILEM TC 178-TMC) to determine the chloride content. 


\section{EXPERIMENTAL RESULTS}

A limited influence of curing conditions on the strength development was observed (Figure 1).

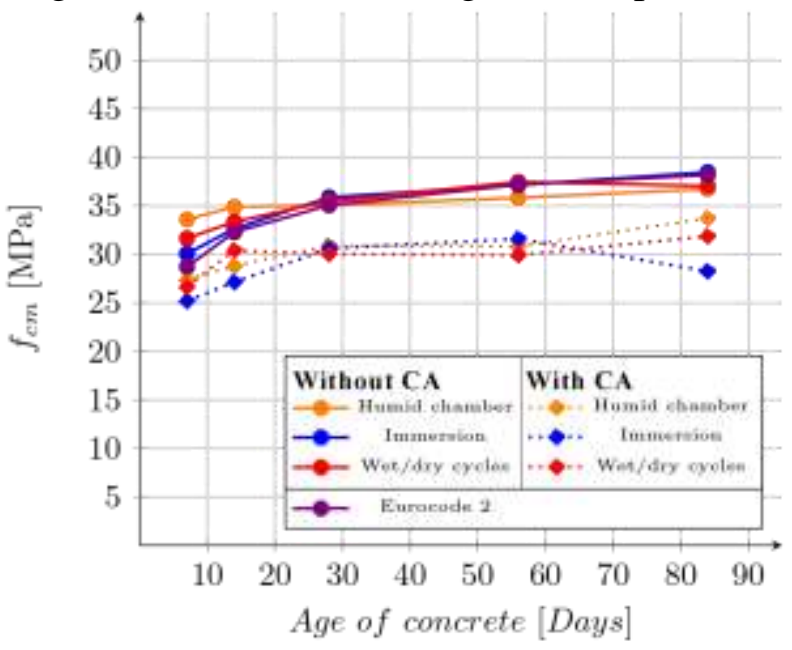

Figure 1. Influence of curing conditions and crystalling admixture on strength development

In order to study the effect of crack self-sealing on the recovery of chloride diffusion resistance, first of all, from the microscope acquired images of the cracks, using an image-editing software, the average crack width $w_{\text {average }}$ was measured and the percentage of crack closure \%sealing was calculated according to Eq. 1

$\%_{\text {healing }}=\frac{w_{\text {initial }}-w_{\text {post-healing }}}{w_{\text {initial }}} \cdot 100$

where: $w_{\text {initial }}$ is the crack width of the newly cracked specimen;

$w_{\text {post-healing }}$ is the crack width of the same specimen after curing;
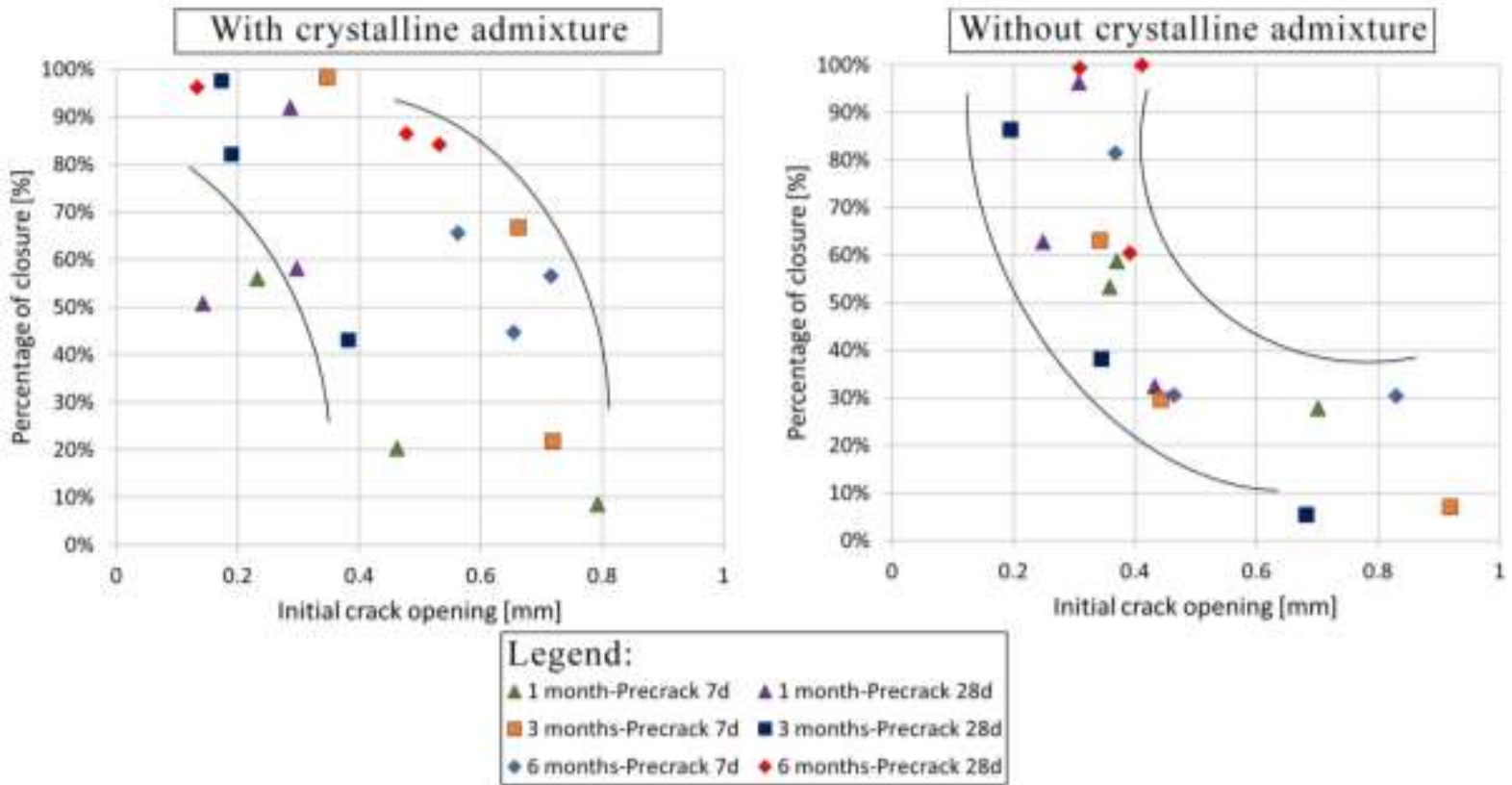

Figure 2. Percentage of crack closure vs. initial crack opening for specimens immersed in a $16.5 \% \mathrm{NaCl}$ aqueous solution. 

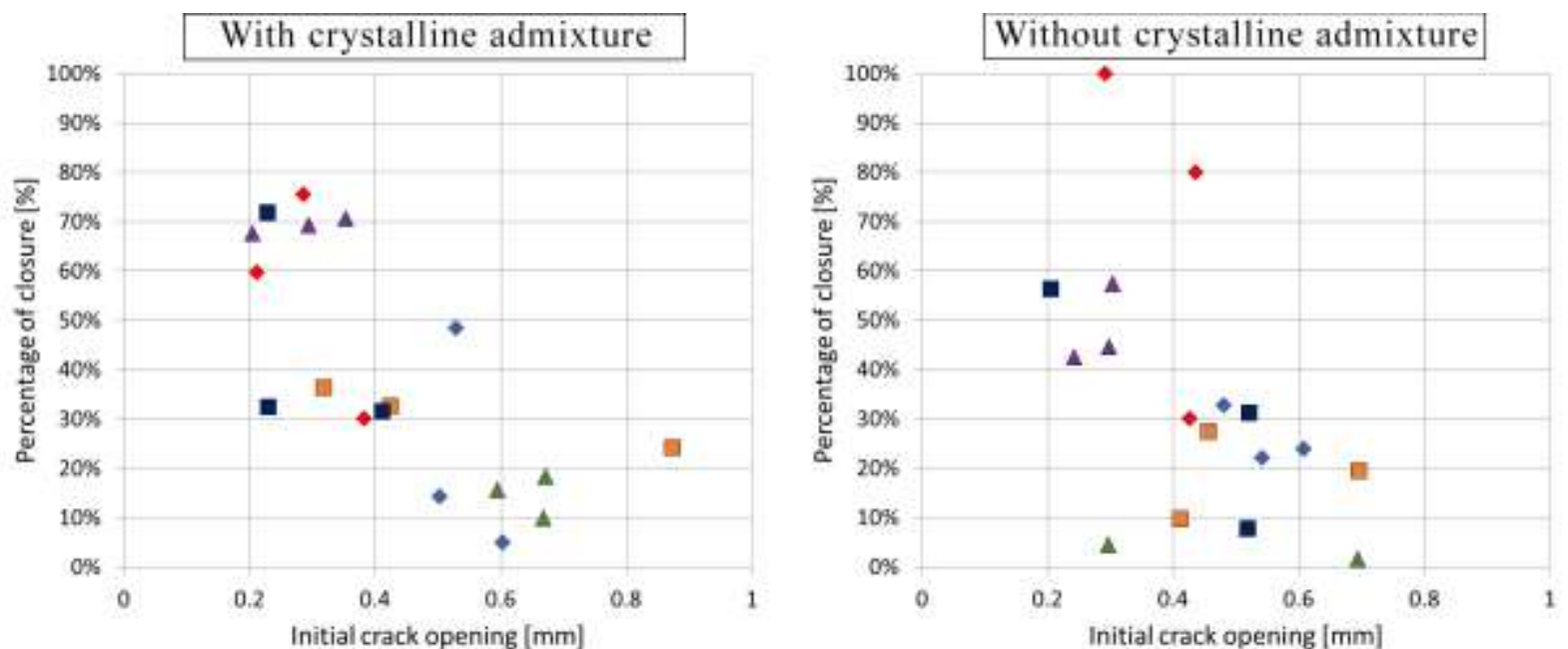

Legend:

41 month-Precrack 7d A 1 month-Precrack 28d

E 3 months-Precrack $7 \mathrm{~d}$ a 3 months-Precrack $28 \mathrm{~d}$

+6 months-Precrack $7 d * 6$ months-Precrack $28 d$

Figure 3. Percentage of crack closure vs. initial crack opening for specimens subjected to wet and dry-cycles in a $16.5 \% \mathrm{NaCl}$ aqueous solution.

Plotting the results obtained for immersed specimens (Figure 2) it is possible to identify at first glance the abovementioned existing relationship between initial crack width and percentage of closure. It is also possible to observe the beneficial effects of the crystalline admixture for wider cracks $(0.5-1 \mathrm{~mm})$. Moreover, focusing on smaller cracks $(<0.4 \mathrm{~mm})$, it can be seen that the concrete samples with the healing agent have the potential to achieve a sealing capacity after 3 months of curing directly comparable to the one obtained after 6 months by the other mix. Considering then the samples subjected to wet/dry cycles (Figure 3) a generally lower healing capacity with respect to submerged samples is observed. Also in this case a relation between initial crack width and crack closure exists and the use of crystalline admixture results on some benefits on the sealing capacity of cracks, even though its positive contribution seems not to be as important as for immersed specimens. Focusing on the pre-cracking age, it can be noted that the cracks obtained for specimens pre-cracked after 7 days are generally wider than those obtained by pre-cracking after 28 days. This outcome is probably due to the fact that when precracking a younger concrete its tensile strength is not fully developed yet, thus making difficult to control the crack width generated through a splitting test.

Finally, chemical titration analyses were performed according to RILEM TC 178-TMC, which allowed the determination of the chloride content as a percentage by mass of concrete. Tests were performed on both uncracked and pre-cracked cylindrical concrete specimens and subjected to both exposure conditions up to 6 months. The experimental data obtained through the chemical tests were then fitted with Fick's second law and, in the case of specimens permanently immersed, the apparent diffusion coefficient $D_{a p p}$ and the surface chloride content was determined. An example of results obtained for specimens both with and without the crystalline admixtures cured under water immersion or wet/dry cycles for one month is shown in Figure 4 ab. Unfortunately, specimens cured for 3 and 6 months immersed in the aqueous solution have suffered from problems related to the formation of an undesired bi-directional diffusion 
phenomenon, due to the non-perfect waterproofness of the lateral surface sealing. The apparent diffusion coefficients obtained following this procedure are summarized in Table 2.

Besides highlighting the dramatic effect that a cracked state (which is the service state of a reinforced concrete structure) has on the chloride permeability, the results also highlight a general improvement for the specimens containing the crystalline admixture with respect to the reference mix ones, though this difference appears decreasing with continued curing and hence continuing healing. Moreover, the longer curing time under wet/dry cycles, and hence the higher sealing, also results in reduction of the chloride permeability coefficient, mainly in the case of concrete containing the crystalline admixture. The higher is the curing time of the pre-cracked sample, the closer the value of the apparent chloride diffusion coefficient D_app to that of an uncracked specimen, especially for specimens containing crystalline admixture.
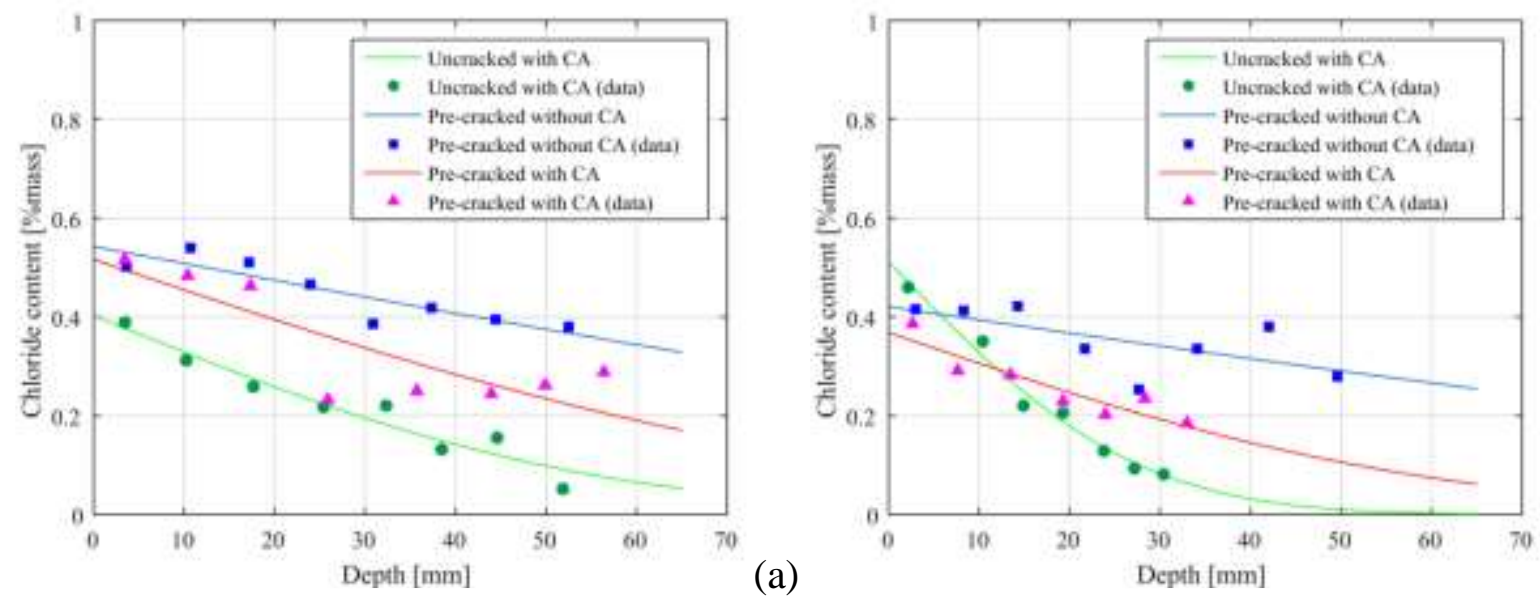

Figure 4. Chloride profiles for specimens immersed continuously (a) and subjected to wet/dry cycles in the $16.5 \% \mathrm{NaCl}$ aqueous solution for 1 month (CA:crystalline admixture).

\begin{tabular}{|l|c|c|}
\hline \multicolumn{3}{|c|}{ Apparent diffusion coefficient $D_{a p p}\left[\mathrm{~m}^{2} / \mathbf{s}\right]$} \\
\hline & Without CA & With crystalline admixture \\
\hline Uncracked, cured for 1 month & $\backslash$ & $3.80 \cdot 10^{-10}$ \\
\hline Pre-cracked at 28 days, cured for 1 month & $3.27 \cdot 10^{-9}$ & $9.21 \cdot 10^{-10}$ \\
\hline
\end{tabular}

Table 2. Apparent diffusion coefficients for specimens immersed in $16.5 \% \mathrm{NaCl}$ solution.

\section{CONCLUSIONS}

In this paper an experimental study of autogenous and crystalline admixture stimulated crack self-sealing has been presented, in which the influence of crack sealing on the reduction of chloride diffusion was assessed. Different exposure conditions were investigated, including water immersion in a $16.5 \% \mathrm{NaCl}$ aqueous solution and wet/dry cycles with the same aqueous solution, together with the influence of pre-cracking ages and healing time. Dependence on crack width and healing time was as expected, with a faster and more effective crack sealing generally achieved by the samples containing the healing agent. Moreover, significant differences could be identified between the values of apparent chloride diffusion coefficient, as affected by the crack sealing of concrete, with and without crystalline admixture. This result is a further proof of the importance of accounting for the presence of cracks when studying chloride diffusion. Such a 
result, besides confirming the importance of considering the cracked state service conditions in assessing the real durability of a structure in its service scenario, could be usefully accounted for when evaluating the effects of healing on the extension of service life in reinforced concrete structures exposed to aggressive environments.

\section{ACKNOWLEDGEMENTS}

The activity described in this paper has been performed in the framework of the project "Rethinking coastal defence and Green-energy Service infrastructures through enHancEddurAbiLity high-performance cement-based materials-ReSHEALience", funded by the European Union Horizon 2020 research and innovation programme under GA No 760824.

\section{REFERENCES}

1. de Belie, N., Gruyaert, E., Al-Tabbaa, A., Antonaci, P., Baera, C., Bajare, D., Darquennes, A., Davies, R., Ferrara, L., Jefferson, T., Litina, C., Miljevic, B., Otlewska, A., Ranogajec, J., Roig-Flores, M., Pain, K., Lukowski, P., Serna, P. Tulliani, J.M., Vucetic, S., Wang, J., Jonkers, H.M.: "A review of self-healing concrete for damage management of structures", Advanced Materials and Interfaces, 5(17), pp. 1-28, 2018.

2. L. Ferrara, T. Van Mullem, M. Alonso, P. Antonaci, R. Borg, E. Cuenca, A. Jefferson, P. Ng, A. Peled, M. Roig-Flores, M. Sánchez, C. Schroefl, P. Serna, D. Snoeck, J. Tulliani and N. De Belie, "Experimental characterization of the self-healing capacity of cement based materials and its effects on the material performance: A state of the art report by COST Action SARCOS WG2," Construction and Building Materials, 167, 2018, pp. 115-142, 2018.

3. B. Savija and E. Schalngen, "Autogeneous healing and chloride ingress in cracked concrete.," Delft University of Technology, 2016.

4. M. Sahmaran, "Effect of flexure induced transverse crack and self-healing on chloride diffusivity of reinforced mortar," Journal of Material Science, 43, pp. 9131-9136, 2007.

5. S. Jacobsen and E. Sellevold, "Self-healing of high strength concrete after deterioration by freeze/thaw," Cement and Concrete Research, vol. 26, pp. 55-62, 1995.

6. R. Borg, E. Cuenca, E. GastaldoBrac and L. Ferrara, "Crack sealing capacity in chloride-rich environments of mortars containing different cement substitutes and crystalline admixtures," Journal of Sustainable Cement-Based Materials, 7(3), pp. 141-159, 2018.

7. M. Li and V. Li, "Cracking and healing of Engineered Cementitious Composites under chloride environment," ACI Materials Journal, 108(3), pp. 333-340, 2011.

8. H. Ling and Q. Chunxiang, "Effects of self-healing cracks in bacterial concrete on the transmission of chloride during electromigration," Construction and Building Materials, 144, pp. 406-411, 2017.

9. B. Van Belleghem, P. Van den Heede, K. Van Tittelboom and e. al, "Quantification of the service life extension and environmental benefit of chloride exposed self-healing concrete," Materials, 10(5), pp. 1-22, 2017.

10. M. Maes and N. De Belie, "Service life estimation of cracked and healed concrete in marine environment," in International Conference on Concrete Repair, Thessaloniki, Greece, 2016.

11. Ferrara, L., Bamonte, P., Suesta, C., Animato, F. et al., "An overview on H2020 project ReSHEALience', Proceeding IABSE Symposium, Guimaraes, 27-39/3/2019, pp. 184-191.

12. E. Cuenca, A. Tejedor and L. Ferrara, "A methodology to assess crack-sealing effectiveness of crystalline admixtures under repeated cracking-healing cycles in Fiber Reinforced Concrete," Construction and Building Materials, 179, pp. 619-632, 2018. 